\title{
Expression of DNA doublestrand repair proteins in oral leukoplakia and the risk of malignant transformation
}

\author{
MINWEN ZHU ${ }^{1}$, WEI LIU ${ }^{2}$, LINJUN SHI $^{1}$, XUAN XIAO $^{1}$, WENYAN WU $^{1}$, LAN WU $^{1}$ and ZENGTONG ZHOU ${ }^{1}$ \\ Departments of ${ }^{1}$ Oral Mucosal Diseases and ${ }^{2}$ Oral and Maxillofacial-Head and Neck Oncology, \\ Shanghai Ninth People's Hospital, Shanghai Jiao Tong University School of Medicine, Shanghai 200011, P.R. China
}

Received May 3, 2016; Accepted January 5, 2018

DOI: $10.3892 /$ ol.2018.8574

\begin{abstract}
The present study assessed the expression of the DNA doublestrand repair (DDR) proteins ATM serine/threonine kinase (ATM), checkpoint kinase 2 (CHEK2) and $\gamma \mathrm{H} 2 \mathrm{~A}$ histone family member X $(\gamma \mathrm{H} 2 \mathrm{AFX})$ in oral leukoplakia (OL) and evaluated their clinical significance and usefulness as biomarkers for predicting OL transformation. Retrospectively, ATM, CHEK 2 and $\gamma \mathrm{H} 2 \mathrm{AFX}$ protein levels were evaluated using immunohistochemical analysis in $61 \mathrm{OL}, 33$ oral squamous cell carcinoma (OSCC) and 15 normal oral mucosa tissues. OL tissues were classified into two groups according to the epithelial dysplasia pathology: The low risk dysplasia group $(n=41)$ and the high-risk dysplasia group $(n=20)$. The results of the present study revealed that the expression of ATM and $\gamma \mathrm{H} 2 \mathrm{AFX}$ in OSCC was significantly increased compared with that in OL with low-risk dysplasia and normal oral mucosa tissues. There was no statistically significant difference in CHEK2 expression among the groups. ATM expression was correlated with that of $\gamma \mathrm{H} 2 \mathrm{AFX}$ in OSCC tissue. The prognostic values of the DDR proteins and their correlation with clinical and pathological parameters were evaluated further in 99 OL patients with low risk dysplasia. Multivariate analysis revealed that increased expression of ATM and $\gamma \mathrm{H} 2 \mathrm{AFX}$ was significantly associated with an increased risk of malignant transformation. Immunohistochemical analysis of ATM and $\gamma \mathrm{H} 2 \mathrm{AFX}$ protein expression provided useful prognostic information on the carcinogenesis of OL. Increased ATM and $\gamma \mathrm{H} 2 \mathrm{AFX}$ expression may indicate a poor prognosis.
\end{abstract}

Correspondence to: Dr Lan Wu or Professor Zengtong Zhou, Department of Oral Mucosal Diseases, Shanghai Ninth People's Hospital, Shanghai Jiao Tong University School of Medicine, 639 Zhizaoju Road, Shanghai 200011, P.R. China

E-mail: teana-wu@hotmail.com

E-mail: zhouzengtong@hotmail.com

Key words: ATM serine/threonine kinase, checkpoint kinase 2, $\gamma \mathrm{H} 2 \mathrm{~A}$ histone family member X, DNA doublestrand repair protein, oral leukoplakia, oral squamous cell carcinoma, prognostic marker

\section{Introduction}

Oral cavity cancer is the most common head and neck cancer (1). It was estimated that 300,400 new cases of oral cavity cancer and 145,400 cases of oral cavity cancer-induced mortality have occurred in 2012 globally (2). Oral leukoplakia (OL) is one of the most common potentially malignant disorders of the oral cavity (3), with a malignant transformation rate of $17-35 \%$ (4). The prognosis and overall survival rate of patients with oral cavity cancer depend on the early detection of any lesion that may identify a patient with increased risk or with early infiltration prior to metastatic disease (3).

DNA doublestrand repair (DDR) is associated with cancer occurrence and progression $(5,6)$. DDR activation occurs almost universally in the earliest stages of carcinogenesis $(7,8)$. Three DDR proteins, ATM serine/threonine kinase (ATM), checkpoint kinase 2 (CHEK2) and $\gamma \mathrm{H} 2 \mathrm{AFX}$ have been observed in numerous premalignant lesions and are associated with the DNA damage response (7,9-11).

ATM activates checkpoint signaling at doublestrand breaks (DSBs), following apoptosis and in response to genotoxic stresses, and thereby functions as a DNA damage sensor. ATM responds to DSBs by phosphorylating numerous substrates and may initiate DSB signaling (12).

CHEK2 is a crucial downstream target of ATM (13). Following DNA damage, ATM preferentially activates CHEK2 (14). Subsequently, activated CHEK2 modulates the activity of cell division cycle $25 \mathrm{C}$, which either facilitates DNA repair or directs the cell to the apoptotic pathway $(15,16)$. The expression of CHEK2 is aberrant in numerous human premalignant and malignant lesions $(8,17,18)$.

$\mathrm{H} 2 \mathrm{~A}$ histone family member $\mathrm{X}$ (H2AFX) is a key DDR component. Within minutes of DNA damage, H2AFX is phosphorylated at its carboxyl terminus to form $\gamma \mathrm{H} 2 \mathrm{AFX}$ at DSB sites (19). The formation of numerous DDR proteins requires H2AFX, indicating that H2AFX serves a key function in the early stages of DDR. H2AFX protein is phosphorylated by ATM, and the level of $\gamma \mathrm{H} 2 \mathrm{AFX}$ is positively associated with the degree of DNA damage (20).

Accordingly, the present study hypothesized that alterations to ATM, CHEK 2 and $\gamma \mathrm{H} 2 \mathrm{AFX}$ may influence the carcinogenesis of OL. As the epithelium of OL is a useful model for monitoring abnormalities and exploring oral carcinogenesis (9), the present study evaluated the protein 
expression of ATM, CHEK 2 and $\gamma \mathrm{H} 2 \mathrm{AFX}$ in OL and OSCC tissues using immunohistochemistry. In addition, the present study assessed the association between the clinicopathological data and expression of these proteins, and their usefulness as biomarkers for predicting the oral carcinogenesis.

\section{Patients and methods}

Patients and collection of clinical specimens. In the present study, all patients with a clinical and pathological diagnosis of OL or OSCC at the Department of Oral Mucosal Diseases at Shanghai Ninth People's Hospital, Shanghai Jiao Tong University School of Medicine (Shanghai, China) were enrolled. The patients underwent biopsy or surgery between January 2005 and December 2014. Normal oral mucosa tissues were obtained during teeth extraction, gingivectomy or other minor surgical procedures. All the study specimens were $10 \%$ formalin-fixed for $24 \mathrm{~h}$ at room temperature and paraffin-embedded. Age, sex, lesion site, dietary habit, smoking history and alcohol use were also collated.

Study design. The present study was approved by the Institutional Review Board of Shanghai Ninth People's Hospital, Shanghai Jiao Tong University School of Medicine. The patients enrolled in the present study were divided into two cohorts. Cohort 1 consisted of 61 OL patients, 33 OSCC patients and 15 healthy individuals. The OL patients were classified into the low risk dysplasia group (OL low risk, $\mathrm{n}=41$ ) and the high-risk dysplasia group (OL high risk, $n=20$ ) according to the degree of epithelial dysplasia: No/questionable/mild dysplasia (low risk) and moderate or severe dysplasia (high risk) (21). All examinations of tissues were determined by light microscope in 4 random fields (magnification, $\mathrm{x} 400$ ). A total of 33 OSCC specimens were confirmed as grade I without lymph node metastasis. The exclusion criteria for patients with OL and OSCC were as follows: (I) Any patient without an initial histopathological examination of OL and OSCC, (II) any patient treated with radiotherapy or chemotherapy prior to sampling and (III) any patient diagnosed with OL and concomitant OSCC at the first visit. The clinical characteristics of cohort 1 were summarized in Table I. Cohort 2 was based on a case-control study and included 99 patients clinically and pathologically diagnosed with OL with low risk dysplasia confirmed by the first biopsy. The inclusion criteria were as follows: (I) Patients were treated with Vita A ( $7.5 \mathrm{mg}$ once a day for 3 months; Shanghai Donghai Pharmaceuticals Co. Ltd., Shanghai, China) and mouth rinsing (primary ingredient is gallnut containing gallic acid, $5 \mathrm{ml}$ three times a day when necessary; Xinjiang Qikang Habowei Pharmaceutical Co. Ltd.) during the disease course, (II) all patients underwent two biopsies and the interval between biopsies was $\geq 3$ years and (III) the lesion sites of each biopsy should remain the same. The exclusion criteria were the same as described for cohort 1. According to the results of the second biopsy, the 99 patients were classified either into the untransformed (UT) group or the malignant-transformed (MT) group.

Immunohistochemical analysis of the expression of ATM, $C H E K 2$ and $\gamma H 2 A F X$. Serial tissue sections $(3 \mu \mathrm{m})$ from the paraffin blocks of normal oral tissues, OL and OSCC were placed in xylene for deparaffinization and in graded alcohol dilutions (ethanol concentration was 80,95 and $100 \%$, respectively) for hydration. Antigen retrieval was performed with $1 \mathrm{mM}$ Tris-EDTA $(\mathrm{pH} 8.0)$ in a $100^{\circ} \mathrm{C}$ water bath for $20 \mathrm{~min}$ and endogenous peroxidase activity was blocked with $3 \%$ hydrogen peroxide for $10 \mathrm{~min}$ at room temperature. Immunohistochemical analysis was performed for the sections. Primary, monoclonal antibodies against ATM (cat. no. ab78; 1:1,000), CHEK2 (cat. no. ab109413; 1:100) and $\gamma \mathrm{H} 2 \mathrm{AFX}$ (cat. no. ab22551; 1:200; all Abcam, Cambridge, UK) $(0.01 \mathrm{~mol} / 1$; pH 7.4; Wuhan Boster Biological Engineering Co., Ltd., Wuhan, China) were used for $1 \mathrm{~h}$ at room temperature. Following rinses with PBS three times for 10 min, a Peroxidase/DAB, K5007 EnVision ${ }^{\mathrm{TM}}$ Detection System kit (ready-to-use, Dako; Agilent Technologies, Inc., Santa Clara, CA, USA) was used to detect the primary antibodies for $1 \mathrm{~h}$ at room temperature, according to the manufacturer's instructions. The sections were subsequently counterstained with $4.8 \mathrm{mg} / \mathrm{ml}$ Harris Hematoxylin for $2 \mathrm{~min}$ at room temperature. Overall, at least three sections were stained to confirm reproducibility. The staining intensity of the cells was observed under a light microscope (Axio Scope A1; Carl Zeiss AG, Oberkochen, Germany). The mean percentage of positive cells was determined in 4 random fields (magnification, x400). To ensure pathological diagnoses were standardized, the cellular localization, intensity, and the percentage of cells with positive ATM, CHEK2 and $\gamma \mathrm{H} 2 \mathrm{AFX}$ staining were assessed by two oral pathologists (Department of Oral Pathology, Shanghai Ninth People's Hospital, Shanghai Jiao Tong University School of Medicine) in a doubleblind manner and a consensus was reached in cases of discrepancy. Cell nuclear and/or cytoplasmic immunoreactivity in the epithelium was considered to indicate positive expression of ATM. Cell nuclear immunoreactivity in the epithelium was considered to indicate positive expression of CHEK 2 and $\gamma \mathrm{H} 2 \mathrm{AFX}$. Positive controls for the antibodies were used according to the manufacturer's instructions. Negative control slides omitted primary antibodies. Positive staining intensity was defined as $0,1,2$, and 3 for no staining, light yellow, yellow brown, and brown, respectively. The scoring method used for ATM and $\gamma \mathrm{H} 2 \mathrm{AFX}$ was referred to by $\mathrm{Hu}$ et al (22). The positive cell percentages of $0,1-25$, 26-50, 51-75, and $>75$ were defined as $0,1,2,3$, and 4 , respectively. The scoring method used for CHEK 2 was a modified version of that used by Alkema et al (23). The positive cell percentages of $0-5,6-25,26-50,51-75$, and $>75$ were defined as $0,1,2,3$, and 4 , respectively. The semiquantitative expression level was evaluated by multiplying the distribution and intensity score. A final score of $<5$ was defined as low expression of ATM and $\gamma \mathrm{H} 2 \mathrm{AFX}$, of $\geq 5$ as high expression of ATM and $\gamma \mathrm{H} 2 \mathrm{AFX}$, of $<7$ as low expression of CHEK2, and of $\geq 7$ as high expression of CHEK2.

Statistical analysis. The SPSS 19.0 software package (IBM Corp., Armonk, NY, USA) was used for all statistical analysis. ATM, CHEK 2 and $\gamma \mathrm{H} 2 \mathrm{AFX}$ expression levels in the normal tissue, OL low risk, OL high risk, and OSCC groups were compared using the Kruskal-Wallis test followed by Dunn's Test. The association between the expression of the proteins and clinicopathological features were assessed using 
Table I. Clinical characteristics of cohort 1.

\begin{tabular}{|c|c|c|c|c|}
\hline Characteristic & Normal $(n=15)$ & OL low risk $(\mathrm{n}=41)$ & OL high risk $(n=20)$ & $\operatorname{OSCC}(n=33)$ \\
\hline \multicolumn{5}{|l|}{ Age } \\
\hline Mean $\pm \mathrm{SD}$ & $44.80 \pm 15.48$ & $56.10 \pm 11.86$ & $57.10 \pm 10.92$ & $56.36 \pm 13.74$ \\
\hline Range & $26-70$ & $35-79$ & $31-82$ & $26-81$ \\
\hline \multicolumn{5}{|l|}{ Sex } \\
\hline Male & 4 & 21 & 13 & 11 \\
\hline Female & 11 & 20 & 7 & 12 \\
\hline \multicolumn{5}{|l|}{ Lesion site } \\
\hline Tongue & 5 & 18 & 15 & 26 \\
\hline Buccal & 5 & 18 & 5 & 6 \\
\hline Gingiva & 3 & 2 & 0 & 1 \\
\hline Palate & 1 & 1 & 0 & 0 \\
\hline Mouth floor & 0 & 0 & 0 & 0 \\
\hline Lip & 1 & 2 & 0 & 0 \\
\hline \multicolumn{5}{|l|}{ Smoking history } \\
\hline Never & 11 & 22 & 12 & 24 \\
\hline Past and present & 4 & 19 & 8 & 9 \\
\hline \multicolumn{5}{|l|}{ Alcohol intake } \\
\hline Never & 8 & 16 & 8 & 14 \\
\hline Past and present & 7 & 25 & 12 & 19 \\
\hline \multicolumn{5}{|l|}{ Dietary habits } \\
\hline Bland & 10 & 21 & 14 & 15 \\
\hline Spicy & 5 & 20 & 6 & 18 \\
\hline
\end{tabular}

OL, oral leukoplakia; $\mathrm{n}$, number of patients; OSCC, oral squamous cell carcinoma; SD, standard deviation.

a $\chi^{2}$ test. Pearson correlation analysis was used to evaluate the association between protein expressions for patients in cohort 1. The Fisher's exact test was used to assess the statistical difference between the expression levels of certain proteins in cohort 2. A logistic regression model was used to evaluate the relative risk of OL malignant transformation. Ranked data were presented as percentage. All tests were two-sided. $\mathrm{P}<0.05$ was considered to indicate a statistically significant difference.

\section{Results}

ATM, CHEK2 and $\gamma H 2 A F X$ expression levels in cohort 1. ATM was primarily expressed in the nucleus and cytoplasm in the epithelium, while CHEK 2 and $\gamma \mathrm{H} 2 \mathrm{AFX}$ were primarily expressed in the nucleus. Cells positive for ATM, CHEK 2 and $\gamma \mathrm{H} 2 \mathrm{AFX}$ expression were detected not only in the stratum basale and stratum spinosum, but also in the stratum granulosum, and in the stratum corneum of certain patients (Fig. 1). ATM expression tended to increase gradually in the normal tissue, OL low risk, OL high risk and OSCC groups during carcinogenesis ( $\mathrm{P}=0.005$; Table II). ATM expression was significantly increased in $29 / 33$ of the samples of the OSCC group, compared with the normal tissue group $(\mathrm{P}=0.008)$. In addition, ATM expression was significantly increased in 23/41 of the samples of the OL low risk group compared with the OSCC group $(\mathrm{P}=0.027)$. In the
OL high-risk group, ATM expression in 13/20 of the samples exhibited no statistically significant difference compared with that in the other three groups, respectively. $\gamma \mathrm{H} 2 \mathrm{AFX}$ expression increased in the groups as carcinogenesis progressed ( $\mathrm{P}=0.001$; Table II). A comparison of the groups revealed that there was a significant difference between the OL low risk and the OSCC groups $(\mathrm{P}=0.014)$, and between the normal tissue and the OSCC groups in $\gamma \mathrm{H} 2 \mathrm{AFX}$ expression $(\mathrm{P}=0.001)$. There was no significant difference in CHEK2 expression among the four groups $(\mathrm{P}=0.074$; Table II). The expression of ATM and $\gamma \mathrm{H} 2 \mathrm{AFX}$ increased in the groups as carcinogenesis progressed. To assess this association, Pearson correlation analysis was performed. The result was statistically significant $[(\mathrm{P}=0.045$; Pearson correlation coefficient $(r)=0.192)]$ among the groups. correlation demonstrated in the OSCC group exhibited $[\mathrm{r}=0.383(\mathrm{P}=0.028)]$

Correlation and clinical significance of ATM and $\gamma H 2 A F X$ expression in normal oral mucosa, OL and OSCC tissues in cohort 1 . The association between ATM and $\gamma \mathrm{H} 2 \mathrm{AFX}$ expression and multiple clinical characteristics of OL in cohort 1 $(n=109)$ was assessed using the $\chi^{2}$ test. Multiple degrees of epithelial dysplasia revealed different expression levels of ATM ( $\mathrm{P}=0.004$; Table III). OSCC and normal tissues demonstrated the highest and lowest percentage, respectively, of ATM expression among the tissues. No correlation was demonstrated between ATM expression and the other clinical characteristics: 


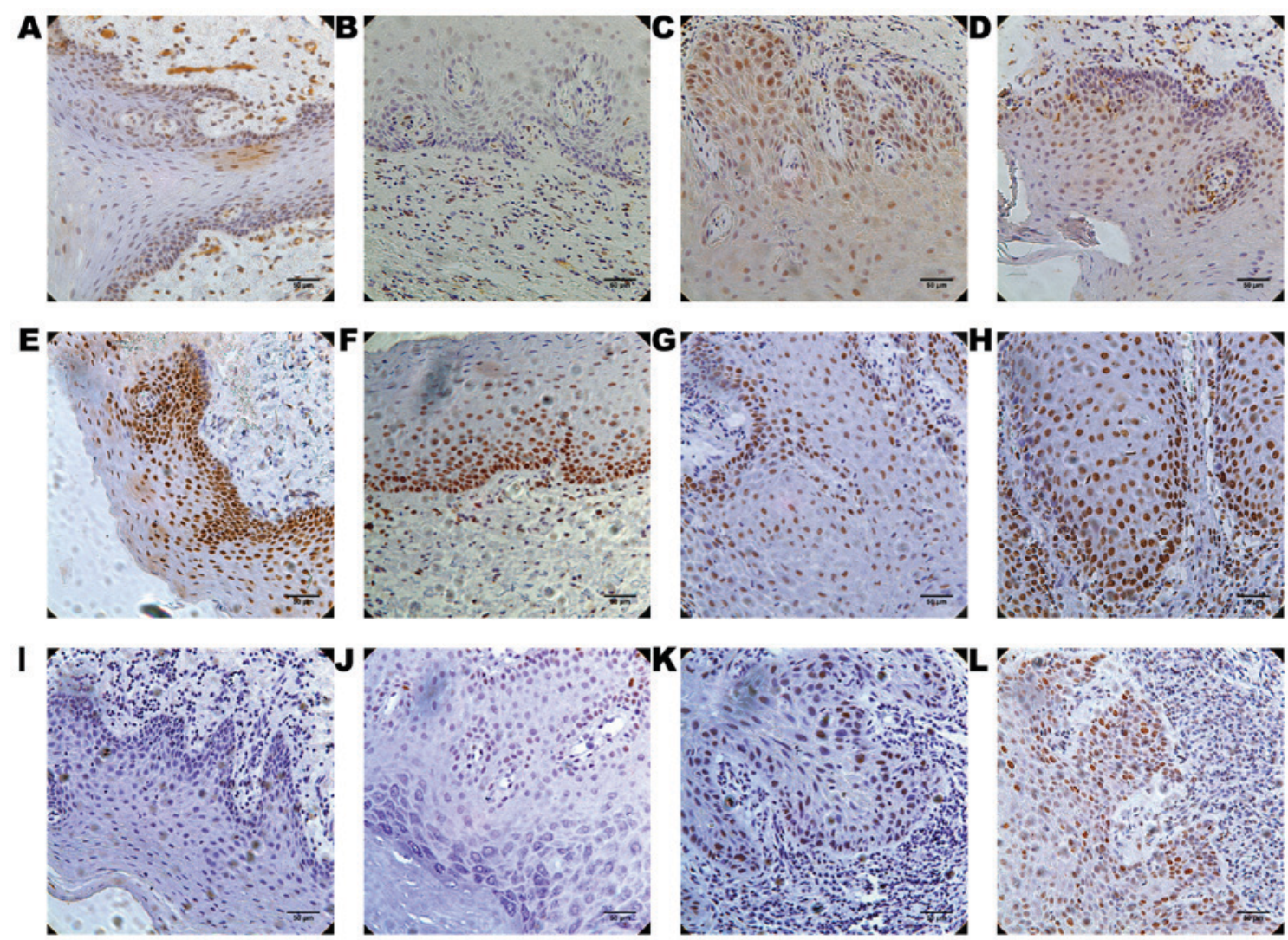

Figure 1. Expression of ATM, CHEK2 and $\gamma \mathrm{H} 2 \mathrm{AFX}$ in the four tissue groups (magnification $\mathrm{x} 400$ ). (A) Expression of ATM in normal oral tissue. (B) Expression of ATM in OL low risk tissue. (C) Expression of ATM in OL high risk tissue. (D) Expression of ATM in OSCC tissue. (E) Expression of CHEK2 in normal oral tissue. (F) Expression of CHEK2 in OL low risk tissue. (G) Expression of CHEK2 in OL high risk tissue. (H) Expression of CHEK2 in OSCC tissue. (I) Expression of $\gamma \mathrm{H} 2 \mathrm{AFX}$ in normal oral tissue. (J) Expression of $\gamma \mathrm{H} 2 \mathrm{AFX}$ in OL low risk tissue. (K) Expression of $\gamma \mathrm{H} 2 \mathrm{AFX}$ in OL high risk tissue. (L) Expression of $\gamma \mathrm{H} 2 \mathrm{AFX}$ in OSCC tissue. ATM, ATM serine/threonine kinase; CHEK2, checkpoint kinase 2; $\gamma \mathrm{H} 2 \mathrm{AFX}, \gamma \mathrm{H} 2 \mathrm{~A}$ histone family member X; OL, oral leukoplakia; OSCC, oral squamous cell carcinoma.

Age, sex, lesion site, dietary habits, smoking history and alcohol use. $\gamma \mathrm{H} 2 \mathrm{AFX}$ expression was also associated with the degree of epithelial dysplasia ( $\mathrm{P}=0.001$; Table IV). OSCC and normal tissues revealed the highest and lowest percentage, respectively, of $\gamma \mathrm{H} 2 \mathrm{AFX}$ expression among the tissues. No clinical characteristics revealed association with $\gamma \mathrm{H} 2 \mathrm{AFX}$ expression.

Identifying candidate DDR proteins in cohort 1 . The selection criteria for candidate DDR proteins were as follows: The expression of candidate DDR proteins increased or decreased successively with respect to increasing grades of carcinogenesis, with significance set at $\mathrm{P}<0.05$ and assessed using the Kruskal-Wallis test. According to the results of the present study, not only did none of the three proteins assessed demonstrate decreased expression as carcinogenesis progressed but ATM and $\gamma \mathrm{H} 2 \mathrm{AFX}$ expression increased as carcinogenesis progressed. ATM and $\gamma \mathrm{H} 2 \mathrm{AFX}$ expression levels were also significantly different between the normal tissue and the OSCC groups, and between the OL low risk and the OSCC groups. Therefore, ATM and $\gamma \mathrm{H} 2 \mathrm{AFX}$ expression was assessed further and validated in the case-control study.

ATM and $\gamma H 2 A F X$ expression in cohort 2. Cohort 2 consisted of 99 patients with OL low risk. On the basis of the second biopsy, these patients were assigned to the UT group $(n=81)$ or the MT group $(\mathrm{n}=18)$. Table V summarizes the characteristics of these patients. High expression of ATM was demonstrated in 54 of the 99 patients (54.5\%). Increased expression of ATM was detected in 40 of the $81(49.4 \%)$ patients in the UT group and in 14 of the 18 (77.8\%) patients in the MT group ( $\mathrm{P}=0.037$; Fig. 2). In addition, 29 of the 99 patients (29.3\%) demonstrated high expression of $\gamma \mathrm{H} 2 \mathrm{AFX}$. Increased expression of $\gamma \mathrm{H} 2 \mathrm{AFX}$ was detected in 19 of the $81(23.5 \%)$ patients in the UT group and in 10 of the 18 (55.6\%) patients in the MT group ( $\mathrm{P}=0.01$; Fig. 2).

High expression of ATM as an independent factor for $O L$ malignant transformation in cohort 2 . To evaluate the risk of OL malignant transformation, clinicopathological parameters, and ATM and $\gamma \mathrm{H} 2 \mathrm{AFX}$ expression were assessed using logistic regression (Table VI). In the univariate analysis, age, sex, lesion site, smoking history, and alcohol use were not significant risk factors for transformation in cohort 2, and high expression of ATM and $\gamma \mathrm{H} 2 \mathrm{AFX}$ was associated with a 3.59-fold [ $(95 \%$ confidence interval (CI), 1.09-11.83; $\mathrm{P}=0.036)]$ and a 4.08 -fold (95\% CI, 1.41-11.80; $\mathrm{P}=0.009$ ), increase in the risk of malignant transformation, respectively. In the multivariate analysis, high expression of ATM and $\gamma \mathrm{H} 2 \mathrm{AFX}$ was also significantly associated with an increased risk of malignant transformation. The adjusted odds ratio for malignant transformation was 4.29 for high ATM expression (95\% CI, 1.22-15.07; $\mathrm{P}=0.023$ ) and 4.79 for high $\gamma \mathrm{H} 2 \mathrm{AFX}$ expression (95\% CI, 1.56-14.73; $\mathrm{P}=0.006)$. 
Table II. ATM, CHEK2 and $\gamma \mathrm{H} 2 \mathrm{AFX}$ expression in cohort $1(\mathrm{n}=109)$.

\begin{tabular}{|c|c|c|c|c|c|c|}
\hline Expression & Total (n) & Normal control (n) & OL low risk (n) & OL high risk (n) & $\operatorname{OSCC}(\mathrm{n})$ & P-value \\
\hline ATM & & & & & & 0.005 \\
\hline Low & 38 & 9 & 18 & 7 & 4 & \\
\hline High & 71 & 6 & 23 & 13 & 29 & \\
\hline CHEK2 & & & & & & 0.074 \\
\hline Low & 20 & 1 & 12 & 1 & 6 & \\
\hline High & 89 & 14 & 29 & 19 & 27 & \\
\hline$\gamma \mathrm{H} 2 \mathrm{AFX}$ & & & & & & 0.001 \\
\hline Low & 79 & 15 & 33 & 15 & 16 & \\
\hline High & 30 & 0 & 8 & 5 & 17 & \\
\hline
\end{tabular}

ATM, ATM serine/threonine kinase; CHEK2, checkpoint kinase 2; $\gamma \mathrm{H} 2 \mathrm{AFX}, \gamma \mathrm{H} 2 \mathrm{~A}$ histone family member X; n, number of patients; OL, oral leukoplakia; OSCC, oral squamous cell carcinoma.

Table III. Association between ATM expression and clinicopathological features in cohort $1(\mathrm{n}=109)$.

\begin{tabular}{|c|c|c|c|c|c|c|}
\hline $\begin{array}{l}\text { Clinicopathological feature } \\
\text { Age, years }\end{array}$ & Total (n) & \multicolumn{2}{|c|}{$\begin{array}{c}\text { Low ATM } \\
\text { expression }(n, \%)\end{array}$} & \multicolumn{2}{|c|}{$\begin{array}{c}\text { High ATM } \\
\text { expression }(n, \%)\end{array}$} & $\begin{array}{r}\text { P-value } \\
0.866\end{array}$ \\
\hline$\leq 60$ & 70 & 24 & 34.3 & 46 & 65.7 & \\
\hline$>60$ & 39 & 14 & 35.9 & 25 & 64.1 & \\
\hline Sex & & & & & & 0.711 \\
\hline Male & 49 & 18 & 36.7 & 31 & 63.3 & \\
\hline Female & 60 & 20 & 33.3 & 40 & 66.7 & \\
\hline Lesion site & & & & & & 0.345 \\
\hline Tongue & 64 & 20 & 31.3 & 44 & 68.8 & \\
\hline Non-tongue & 45 & 18 & 40.0 & 27 & 60.0 & \\
\hline Dietary habits & & & & & & 0.333 \\
\hline Bland & 62 & 24 & 38.7 & 38 & 61.3 & \\
\hline Spicy & 47 & 14 & 29.8 & 33 & 70.2 & \\
\hline Smoking history & & & & & & 0.261 \\
\hline Never & 68 & 21 & 30.9 & 47 & 69.1 & \\
\hline Past and present & 41 & 17 & 41.5 & 24 & 58.5 & \\
\hline Alcohol intake & & & & & & 0.345 \\
\hline Never & 45 & 18 & 40.0 & 27 & 60.0 & \\
\hline Past and present & 64 & 20 & 31.3 & 44 & 68.8 & \\
\hline Epithelial dysplasia & & & & & & 0.004 \\
\hline Normal & 15 & 9 & 60.0 & 6 & 40.0 & \\
\hline OL low risk & 41 & 18 & 43.9 & 23 & 56.1 & \\
\hline OL high risk & 20 & 7 & 35.0 & 13 & 65.0 & \\
\hline OSCC & 33 & 4 & 12.1 & 29 & 87.9 & \\
\hline
\end{tabular}

Non-tongue denotes buccal, gingiva, palate, mouth floor, or lip. ATM, ATM serine/threonine kinase; n, number of patients; OL, oral leukoplakia; OSCC, oral squamous cell carcinoma.

\section{Discussion}

To the best of our knowledge, the present study is the first to evaluate ATM, CHEK2 and $\gamma \mathrm{H} 2 \mathrm{AFX}$ expression in patients with OL with multiple degrees of epithelial dysplasia and to assess the functions of these proteins in predicting the risk of OSCC in two independent cohorts using immunohistochemical analysis. ATM serves a key function in the DNA 
Table IV. Association between $\gamma \mathrm{H} 2 \mathrm{AFX}$ expression and clinicopathological features in cohort $1(\mathrm{n}=109)$.

\begin{tabular}{|c|c|c|c|c|c|c|}
\hline $\begin{array}{l}\text { Clinicopathological feature } \\
\text { Age, years }\end{array}$ & Total (n) & \multicolumn{2}{|c|}{$\begin{array}{c}\text { Low } \gamma \mathrm{H} 2 \mathrm{AFX} \\
\text { expression }(\mathrm{n}, \%)\end{array}$} & \multicolumn{2}{|c|}{$\begin{array}{c}\text { High } \gamma \mathrm{H} 2 \mathrm{AFX} \\
\text { expression }(\mathrm{n}, \%)\end{array}$} & $\frac{\text { P-value }}{0.905}$ \\
\hline$\leq 60$ & 70 & 51 & 72.9 & 19 & 27.1 & \\
\hline$>60$ & 39 & 28 & 71.8 & 11 & 28.2 & \\
\hline Sex & & & & & & 0.834 \\
\hline Male & 49 & 36 & 73.5 & 13 & 26.5 & \\
\hline Female & 60 & 43 & 71.7 & 17 & 28.3 & \\
\hline Lesion site & & & & & & 0.056 \\
\hline Tongue & 64 & 42 & 65.6 & 22 & 34.4 & \\
\hline Non-tongue & 45 & 37 & 82.2 & 8 & 17.8 & \\
\hline Dietary habits & & & & & & 0.402 \\
\hline Bland & 62 & 43 & 69.4 & 19 & 30.6 & \\
\hline Spicy & 47 & 36 & 76.6 & 11 & 23.4 & \\
\hline Smoking history & & & & & & 0.9 \\
\hline Never & 68 & 49 & 72.1 & 19 & 27.9 & \\
\hline Past and present & 41 & 30 & 73.2 & 11 & 26.8 & \\
\hline Alcohol intake & & & & & & 0.14 \\
\hline Never & 45 & 36 & 80.0 & 9 & 20.0 & \\
\hline Past and present & 64 & 43 & 67.2 & 21 & 32.8 & \\
\hline Epithelial dysplasia & & & & & & 0.001 \\
\hline Normal & 15 & 15 & 100.0 & 0 & 0.0 & \\
\hline OL low risk & 41 & 33 & 80.5 & 8 & 19.5 & \\
\hline OL high risk & 20 & 15 & 75.0 & 5 & 25.0 & \\
\hline OSCC & 33 & 16 & 48.5 & 17 & 51.5 & \\
\hline
\end{tabular}

Non-tongue denotes buccal, gingiva, palate, mouth floor, or lip. $\gamma \mathrm{H} 2 \mathrm{AFX}, \gamma \mathrm{H} 2 \mathrm{~A}$ histone family member X; n, number of patients; OL, oral leukoplakia; OSCC, oral squamous cell carcinoma.

DSB-induced signaling cascade. Tumorigenic events that occur early in the progression of major types of human cancer activate ATM-regulated cell cycle checkpoints and thereby an inducible barrier that inhibits tumor progression and genetic instability $(7,24)$. A previous study has demonstrated that ATM expression was increased in certain types of cancer tissue compared with that in benign tumorous lesions and normal tissues (22). Other previous studies have suggested that ATM potentially represents a promising indicator for hyperplasia and cancer, and may serve as a useful marker for identifying patients with poor prognosis $(25,26)$. Raynaud et al (10) demonstrated that the difference in ATM activation between normal and precancerous tissues was not significant, though ATM expression differed significantly between precancerous and cancerous tissues. The results of the aforementioned studies support those of the present study.

He et al (9) indicated that ATM protein expression was higher in OL compared with that in normal oral tissue, but demonstrated no significant difference between OL and OSCC tissues in ATM protein expression. The present study dynamically observed the activation of the DNA damage signaling pathway in normal oral mucosa, OL (low risk dysplasia and high risk dysplasia) and OSCC tissues in a large population. In contrast to the results demonstrated by
He et al (9) those demonstrated in the present study revealed that ATM expression gradually increased as OL progressed to OSCC. In addition, the present study revealed a significant difference in ATM expression between OL with low risk dysplasia and OSCC. In the present study, ATM expression correlated with the degree of epithelial dysplasia during carcinogenesis and age, sex, lesion site, dietary habits, smoking history, and alcohol use were not significant factors in the expression of ATM. Therefore, the results of the present study indicated that ATM was activated in oral precancerous lesions and served a function in the early stages of oral carcinogenesis.

One of the proteins phosphorylated following DNA damage, a process initiated by ATM, is H2AFX, which, in phosphorylated form $(\gamma \mathrm{H} 2 \mathrm{AFX})$, functions as a specific indicator for the presence of DSBs (27). Increased $\gamma \mathrm{H} 2 \mathrm{AFX}$ expression may result in increased radiosensitivity (28). Multiple studies have revealed that $\gamma \mathrm{H} 2 \mathrm{AFX}$ expression is increased in certain types of cancer and their premalignant lesions $(8,22,29,30)$, which supports the results of the present study. Overexpression of $\gamma \mathrm{H} 2 \mathrm{AFX}$ may represent an independent prognostic indicator of a poor overall patient survival rate $(31,32)$. In contrast to the results of the present study, Chou et al (33) reported that $\gamma \mathrm{H} 2 \mathrm{AFX}$ expression was increased in dysplastic epithelium and significantly 
Table V. Clinical characteristics of cohort 2.

\begin{tabular}{|c|c|c|}
\hline Characteristic & $\mathrm{UT}(\mathrm{n}=81)$ & $\operatorname{MT}(n=18)$ \\
\hline \multicolumn{3}{|l|}{ Age, years } \\
\hline Mean \pm SD & $56.53 \pm 11.27$ & $54.83 \pm 11.63$ \\
\hline Range & $31-82$ & $35-71$ \\
\hline \multicolumn{3}{|l|}{ Sex } \\
\hline Male & 44 & 8 \\
\hline Female & 37 & 10 \\
\hline \multicolumn{3}{|l|}{ Lesion site } \\
\hline Tongue & 44 & 13 \\
\hline Buccal & 32 & 3 \\
\hline Gingiva & 2 & 1 \\
\hline Palate & 1 & 0 \\
\hline Mouth floor & 0 & 0 \\
\hline Lip & 2 & 1 \\
\hline \multicolumn{3}{|l|}{ Dietary habits } \\
\hline Bland & 50 & 11 \\
\hline Spicy & 31 & 7 \\
\hline \multicolumn{3}{|l|}{ Smoking history } \\
\hline Never & 50 & 11 \\
\hline Past and present & 31 & 7 \\
\hline \multicolumn{3}{|l|}{ Alcohol intake } \\
\hline Never & 33 & 6 \\
\hline Past and present & 48 & 12 \\
\hline \multicolumn{3}{|l|}{ ATM expression } \\
\hline Low & 41 & 4 \\
\hline High & 40 & 14 \\
\hline \multicolumn{3}{|c|}{$\gamma \mathrm{H} 2 \mathrm{AFX}$ expression } \\
\hline Low & 62 & 8 \\
\hline High & 19 & 10 \\
\hline
\end{tabular}

SD, standard deviation; ATM, ATM serine/threonine kinase; $\gamma \mathrm{H} 2 \mathrm{AFX}, \gamma \mathrm{H} 2 \mathrm{~A}$ histone family member $\mathrm{X}$.

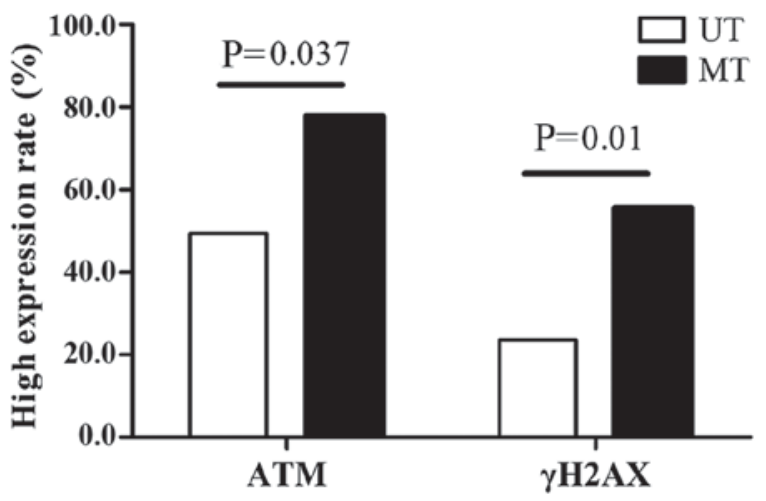

Figure 2. Frequency of increased ATM and $\gamma \mathrm{H} 2 \mathrm{AFX}$ expression in oral leukoplakia low risk tissue. ATM, ATM serine/threonine kinase; $\gamma \mathrm{H} 2 \mathrm{AFX}, \gamma \mathrm{H} 2 \mathrm{~A}$ histone family member X; UT, untransformed; MT, malignant-transformed.

decreased in OSCC tissue. The results of the present study revealed that $\gamma \mathrm{H} 2 \mathrm{AFX}$ expression increased in OSCC tissue
Table VI. Logistic regression analysis of the potential risk of oral cancer.

\begin{tabular}{lll}
\hline Characteristic & OR $(95 \%$ CI $)$ & P-value \\
\hline Univariate analysis & & \\
Age & $1.36(0.48-3.82)$ & 0.560 \\
Sex & $0.67(0.24-1.88)$ & 0.449 \\
Lesion site & $2.19(0.71-6.70)$ & 0.171 \\
Dietary habits & $1.03(0.36-2.93)$ & 0.961 \\
Smoking history & $1.03(0.36-2.93)$ & 0.961 \\
Alcohol intake & $1.38(0.47-4.03)$ & 0.562 \\
High ATM expression & $3.59(1.09-11.83)$ & 0.036 \\
High $\gamma$ H2AFX expression & $4.08(1.41-11.80)$ & 0.009 \\
Multivariate analysis & & \\
High ATM expression & $4.29(1.22-15.07)$ & 0.023 \\
High $\gamma$ H2AFX expression & $4.79(1.56-14.73)$ & 0.006 \\
\hline
\end{tabular}

OR, odds ratio; CI, confidence interval; ATM, ATM serine/threonine kinase; $\gamma \mathrm{H} 2 \mathrm{AFX}, \gamma \mathrm{H} 2 \mathrm{~A}$ histone family member $\mathrm{X}$.

with increasing disease severity; this discrepancy between the aforementioned and present study may be due to the difference in the OSCC tumor differentiation grade selected. In the present study, similar to ATM expression, $\gamma \mathrm{H} 2 \mathrm{AFX}$ expression correlated with the degree of epithelial dysplasia, according to the results of the associations between clinicopathological features and $\gamma \mathrm{H} 2 \mathrm{AFX}$ expression. Detecting $\gamma \mathrm{H} 2 \mathrm{AFX}$ expression may help to evaluate precancerous oral cavity lesions and monitor cancer progression.

CHEK2 serves a key function in inhibiting cell cycle progression in response to the DNA damage pathway (34). In multiple types of solid tumor, CHEK2 expression was decreased compared with that in normal tissues (35-37). CHEK2 expression in oral precancerous lesions is rarely assessed. In the present study, the expression of CHEK2 protein altered during oral carcinogenesis. There were no significant differences between any two groups of the four during carcinogenesis. Based on these conflicting results, the present study suggested that: (I) Aberrant CHEK2 protein may be functionally defective and regulated by other, unknown upstream proteins during DDR; (II) CHEK2 protein expression is regulated differently depending on the type of carcinoma; (III) the ATM-CHEK2 pathway may not be associated with oral carcinoma or precancerous lesions or (IV) more complex signaling pathways may participate in the DNA damage response.

Pearson correlation analysis of cohort 1 demonstrated that $\gamma \mathrm{H} 2 \mathrm{AFX}$ and ATM expression was correlated $(\mathrm{P}=0.045 ; \mathrm{r}=0.192)$, particularly in OSCC tissue $(\mathrm{P}=0.028$; $\mathrm{r}=0.383)$. Therefore, the present study suggested that the ATM- $\gamma \mathrm{H} 2 \mathrm{AFX}$ pathway contributes to the DNA damage response.

For cohort 2, the present study assessed the prognostic value of ATM and $\gamma \mathrm{H} 2 \mathrm{AFX}$ expression and evaluate whether the prognostic value was independent of clinicopathological factors. Univariate and multivariate analysis revealed that increased ATM and $\gamma \mathrm{H} 2 \mathrm{AFX}$ expression was significantly 
associated with an increased risk of transformation $(\mathrm{P}<0.05)$. The results of the present study indicated that increased ATM and $\gamma \mathrm{H} 2 \mathrm{AFX}$ expression served as an independent predictor of carcinogenesis. However, age, sex, lesion site, dietary habits, smoking history, and alcohol use were not revealed to be significant risk factors for OL malignant transformation in the cohort 2 , a result that reflects that of multiple previous studies (38-40).

To conclude, the results of the present study suggested that ATM and $\gamma \mathrm{H} 2 \mathrm{AFX}$ expression in OL tissue was associated with oral cancer progression. Immunohistochemical staining of ATM and $\gamma \mathrm{H} 2 \mathrm{AFX}$ may represent a promising technique for the early identification and risk evaluation of OSCC in patients with precancerous oral lesions. Further studies are required to assess the function of ATM and $\gamma \mathrm{H} 2 \mathrm{AFX}$ in oral carcinogenesis, including for grade I, II and III OSCC. Further study of the mechanisms underlying DNA damage and response in OL tissue is also required.

\section{Acknowledgements}

The abstract was presented at the 35th Annual Meeting of the International Association for Dental Research Korean Division on June 25th 2016 in Seoul, Republic of Korea. The authors would like to thank Professor Jiang Li and Dr Lizhen Wang (Department of Oral Pathology, Shanghai Ninth People's Hospital, Shanghai Jiao Tong University School of Medicine) for their technical assistance.

\section{Funding}

The present study was supported by the National Natural Science Foundation of China (grant no. 81400513) and the Science and Technology Commission of Shanghai (grant no. 14401931600).

\section{Availability of data and materials}

The datasets used and/or analyzed during the current study are available from the corresponding author on reasonable request.

\section{Authors' contributions}

LW, ZZ and WL conceived and designed the study. MZ, LS, $\mathrm{XX}$ and WW performed the experiments. MZ analyzed the data and wrote the manuscript. LW and $\mathrm{ZZ}$ reviewed and edited the manuscript. All authors read and approved the final manuscript.

\section{Ethics approval and consent to participate}

The present study was approved by the Institutional Review Board of Shanghai Ninth People's Hospital, Shanghai Jiao Tong University School of Medicine.

\section{Consent for publication}

The subjects or parent/guardian that participated in the present study provided written informed consents for publication.

\section{Competing interests}

The authors declare that they have no competing interests.

\section{Authors' information}

LW, Department of Oral Mucosal Diseases, Shanghai Ninth People's Hospital, Shanghai Jiao Tong University School of Medicine, committee member of the Oral Mucosal Disease Professional Committee of Shanghai Stomatological Association; committee member of Chinese and Western medicine professional committee of Chinese Stomatological Association.

ZZ, Department of Oral Mucosal Diseases, Shanghai Ninth People's Hospital, Shanghai Jiao Tong University School of Medicine, former chairman of the oral mucosal disease professional committee of Chinese Stomatological Association; former chairman of the oral mucosal disease professional committee of Shanghai Stomatological Association.

\section{References}

1. Chi AC, Day TA and Neville BW: Oral cavity and oropharyngeal squamous cell carcinoma-an update. CA Cancer J Clin 65: 401-421, 2015.

2. Torre LA, Bray F, Siegel RL, Ferlay J, Lortet-Tieulent J and Jemal A: Global cancer statistics, 2012. CA Cancer J Clin 65: 87-108, 2015.

3. Boy SC: Leukoplakia and erythroplakia of the oral mucosa-a brief overview. SADJ 67: 558-560, 2012.

4. van der Waal I, Schepman KP, van der Meij EH and Smeele LE: Oral leukoplakia: A clinicopathological review. Oral Oncol 33: 291-301, 1997.

5. Khanna KK and Jackson SP: DNA doublestrand breaks: Signaling, repair and the cancer connection. Nat Genet 27: 247-254, 2001.

6. Peng A and Maller JL: Serine/threonine phosphatases in the DNA damage response and cancer. Oncogene 29: 5977-5988, 2010.

7. Bartkova J, Horejsi Z, Koed K, Krämer A, Tort F, Zieger K, Guldberg P, Sehested M, Nesland JM, Lukas C, et al: DNA damage response as a candidate anti-cancer barrier in early human tumorigenesis. Nature 434: 864-870, 2005.

8. Gorgoulis VG, Vassiliou LV, Karakaidos P, Zacharatos P, Kotsinas A, Liloglou T, Venere M, Ditullio RA Jr, Kastrinakis NG, Levy B, et al: Activation of the DNA damage checkpoint and genomic instability in human precancerous lesions. Nature 434: 907-913, 2005.

9. He Y, Chen Q and Li B: ATM in oral carcinogenesis: Association with clinicopathological features. J Cancer Res Clin Oncol 134: 1013-1020, 2008.

10. Raynaud CM, Hernandez J, Llorca FP, Nuciforo P, Mathieu MC, Commo F, Delaloge S, Sabatier L, André F and Soria JC: DNA damage repair and telomere length in normal breast, preneoplastic lesions, and invasive cancer. Am J Clin Oncol 33: 341-345, 2010.

11. Yuan J, Adamski R and Chen J: Focus on histone variant H2AFX: To be or not to be. FEBS Lett 584: 3717-3724, 2010.

12. Shiloh Y: ATM and related protein kinases: Safeguarding genome integrity. Nat Rev Cancer 3: 155-168, 2003.

13. Bartek J and Lukas J: Chk1 and CHEK2 kinases in checkpoint control and cancer. Cancer Cell 3: 421-429, 2003.

14. Zhou BB and Elledge SJ: The DNA damage response: Putting checkpoints in perspective. Nature 408: 433-439, 2000.

15. Peng CY, Graves PR, Thoma RS, Wu Z, Shaw AS and Piwnica-Worms H: Mitotic and G2 checkpoint control: Regulation of 14-3-3 protein binding by phosphorylation of Cdc25C on serine-216. Science 277: 1501-1505, 1997.

16. Chang CC, Hung CM, Yang YR, Lee MJ and Hsu YC: Sulforaphane induced cell cycle arrest in the G2/M phase via the blockade of cyclin B1/CDC2 in human ovarian cancer cells. J Ovarian Res 6: 41, 2013. 
17. Matthews TP, Jones AM and Collins I: Structure-based design discovery and development of checkpoint kinase inhibitors as potential anticancer therapies. Expert Opin Drug Discov 8: 621-640, 2013.

18. Lantuejoul S, Raynaud C, Salameire D, Gazzeri S, Moro-Sibilot D, Soria JC, Brambilla C and Brambilla E: Telomere maintenance and DNA damage responses during lung carcinogenesis. Clin Cancer Res 16: 2979-2988, 2010.

19. Bonner WM, Redon CE, Dickey JS, Nakamura AJ, Sedelnikova OA, Solier S and Pommier Y: GammaH2AFX and cancer. Nat Rev Cancer 8: 957-967, 2008.

20. Rogakou EP, Boon C, Redon C and Bonner WM: Megabase chromatin domains involved in DNA doublestrand breaks in vivo. J Cell Biol 146: 905-916, 1999.

21. Warnakulasuriya S, Reibel J, Bouquot J and Dabelsteen E: Oral epithelial dysplasia classification systems: Predictive value utility, weaknesses and scope for improvement. J Oral Pathol Med 37: 127-133, 2008.

22. Hu JL, Hu SS, Hou XX, Zhu X, Cao J, Jiang LH and Ge MH: Abnormal expression of DNA Double-Strand breaks related genes, ATM and GammaH2AFX, in thyroid carcinoma. Int J Endocrinol 2015: 136810, 2015.

23. Alkema NG, Tomar T, van der Zee AG, Everts M, Meersma GJ, Hollema H, de Jong S, van Vugt MA and Wisman GB: Checkpoint kinase 2 (Chek2) supports sensitivity to platinum-based treatment in high grade serous ovarian cancer. Gynecol Oncol 133 . 591-598, 2014.

24. Bartkova J, Rezaei N, Liontos M, Karakaidos P, Kletsas D, Issaeva N, Vassiliou LV, Kolettas E, Niforou K, Zoumpourlis VC, et al: Oncogene-induced senescence is part of the tumorigenesis barrier imposed by DNA damage checkpoints. Nature 444: 633-637, 2006.

25. Wang YH, Li F, Luo B, Wang XH, Sun HC, Liu S, Cui YQ and Xu XX: A side population of cells from a human pancreatic carcinoma cell line harbors cancer stem cell characteristics. Neoplasma 56: 371-378, 2009.

26. Dou J, Wen P, Hu W, Li Y, Wu Y, Liu C, Zhao F, Hu K, Wang J, Jiang C, et al: Identifying tumor stem-like cells in mouse melanoma cell lines by analyzing the characteristics of side population cells. Cell Biol Int 33: 807-815, 2009.

27. Takahashi A and Ohnishi T: Does gammaH2AFX foci formation depend on the presence of DNA double strand breaks? Cancer Lett 229: 171-179, 2005.

28. Qiang L, Yang Y, Ma YJ, Chen FH, Zhang LB, Liu W, Qi Q, Lu N, Tao L, Wang XT, et al: Isolation and characterization of cancer stem like cells in human glioblastoma cell lines. Cancer Lett 279: 13-21, 2009.

29. Wasco MJ and Pu RT: Utility of antiphosphorylated H2AFX antibody (gamma-H2AFX) in diagnosing metastatic renal cell carcinoma. Appl Immunohistochem Mol Morphol 16: 349-356, 2008 .
30. Mah LJ, El-Osta A and Karagiannis TC: GammaH2AFX as a molecular marker of aging and disease. Epigenetics 5: 129-136, 2010.

31. Matthaios D, Foukas PG, Kefala M, Hountis P, Trypsianis G, Panayiotides IG, Chatzaki E, Pantelidaki E, Bouros D, Karakitsos P and Kakolyris S: $\gamma$-H2AFX expression detected by immunohistochemistry correlates with prognosis in early operable non-small cell lung cancer. Onco Targets Ther 5: 309-314, 2012.

32. Oliveira-Costa JP, Oliveira LR, Zanetti R, Zanetti JS, da Silveira GG, Chavichiolli Buim ME, Zucoloto S, Ribeiro-Silva A and Soares FA: BRCA1 and $\gamma \mathrm{H} 2 \mathrm{AFX}$ as independent prognostic markers in oral squamous cell carcinoma. Oncoscience 1: 383-391, 2014.

33. Chou SJ and Alawi F: Expression of DNA damage response biomarkers during oral carcinogenesis. Oral Surg Oral Med Oral Pathol Oral Radiol Endod 111: 346-353, 2011.

34. Inoue K, Fry EA and Taneja P: Recent progress in mouse models for tumor suppressor genes and its implications in human cancer. Clin Med Insights Oncol 7: 103-122, 2013.

35. Sullivan A, Yuille M, Repellin C, Reddy A, Reelfs O, Bell A, Dunne B, Gusterson BA, Osin P, Farrell PJ, et al: Concomitant inactivation of p53 and Chek 2 in breast cancer. Oncogene 21: 1316-1324, 2002.

36. Zhang P, Wang J, Gao W, Yuan BZ, Rogers J and Reed E: CHEK2 kinase expression is down-regulated due to promoter methylation in non-small cell lung cancer. Mol Cancer 3: 14, 2004.

37. Kilpivaara O, Bartkova J, Eerola H, Syrjäkoski K, Vahteristo $\mathrm{P}$ Lukas J, Blomqvist C, Holli K, Heikkilä P, Sauter G, et al: Correlation of CHEK2 protein expression and c.1100delC mutation status with tumor characteristics among unselected breast cancer patients. Int J Cancer 113: 575-580, 2005.

38. Liu W, Wu L, Shen XM, Shi LJ, Zhang CP, Xu LQ and Zhou ZT: Expression patterns of cancer stem cell markers ALDH1 and CD133 correlate with a high risk of malignant transformation of oral leukoplakia. Int J Cancer 132: 868-874, 2013.

39. Liu W, Bao ZX, Shi LJ, Tang GY and Zhou ZT: Malignant transformation of oral epithelial dysplasia: Clinicopathological risk factors and outcome analysis in a retrospective cohort of 138 cases. Histopathology 59: 733-740, 2011.

40. Liu W, Wang YF, Zhou HW, Shi P, Zhou ZT and Tang GY: Malignant transformation of oral leukoplakia: A retrospective cohort study of 218 Chinese patients. BMC Cancer 10: 685, 2010.

This work is licensed under a Creative Commons Attribution-NonCommercial-NoDerivatives 4.0 International (CC BY-NC-ND 4.0) License. 